\title{
Hydration water and microstructure in calcium silicate and aluminate hydrates
}

\author{
Emiliano Fratini ${ }^{1}$, Francesca Ridi ${ }^{1}$, Sow-Hsin Chen $^{2}$ and \\ Piero Baglioni ${ }^{1,2,3}$ \\ ${ }^{1}$ Department of Chemistry and CSGI, University of Florence, via della Lastruccia 3-Sesto \\ Fiorentino, I-50019 Florence, Italy \\ 2 Department of Nuclear Science and Engineering, Massachusetts Institute of Technology, \\ Cambridge, MA 02139, USA \\ E-mail: piero.baglioni@unifi.it
}

Received 16 March 2006

Published 24 August 2006

Online at stacks.iop.org/JPhysCM/18/S2467

\begin{abstract}
Understanding the state of the hydration water and the microstructure development in a cement paste is likely to be the key for the improvement of its ultimate strength and durability. In order to distinguish and characterize the reacted and unreacted water, the single-particle dynamics of water molecules in hydrated calcium silicates $\left(\mathrm{C}_{3} \mathrm{~S}, \mathrm{C}_{2} \mathrm{~S}\right)$ and aluminates $\left(\mathrm{C}_{3} \mathrm{~A}, \mathrm{C}_{4} \mathrm{AF}\right)$ were studied by quasi-elastic neutron scattering, QENS. The time evolution of the immobile fraction represents the hydration kinetics and the mobile fraction follows a non-Debye relaxation. Less sophisticated, but more accessible and cheaper techniques, like differential scanning calorimetry, DSC, and nearinfrared spectroscopy, NIR, were validated through QENS results and they allow one to easily and quantitatively follow the cement hydration kinetics and can be widely applied on a laboratory scale to understand the effect of additives (i.e., superplasticizers, cellulosic derivatives, etc) on the thermodynamics of the hydration process. DSC provides information on the free water index and on the activation energy involved in the hydration process while the NIR band at $7000 \mathrm{~cm}^{-1}$ monitors, at a molecular level, the increase of the surface-interacting water. We report as an example the effect of two classes of additives widely used in the cement industry: superplasticizers, SPs, and cellulose derivatives. SPs interact at the solid surface, leading to a consistent increment of the activation energy for the processes of nucleation and growth of the hydrated phases. In contrast, the cellulosic additives do not affect the nucleation and growth activation energy, but cause a significant increment in the water availability: in other words the hydration process is more efficient without any modification of the solid/liquid interaction, as also evidenced by the ${ }^{1} \mathrm{H}-\mathrm{NMR}$. Additional information is obtained by scanning electron microscopy (SEM), ultra small
\end{abstract}

3 Author to whom any correspondence should be addressed. www.csgi.unifi.it. 
angle neutron scattering (USANS) and wide angle x-ray scattering (WAXD) that characterize how additives affect both the hydrated microstructure development and the original grain size. In particular, SPs alter the morphology of the hydrated phases, which no longer grow with the classic fibrillar structure on the grain surface, but nucleate in solution as globular structures. All this information converges in a quantitative, and at molecular level, description of the mechanisms involved in the setting process of one of the materials most widely used by human beings.

(Some figures in this article are in colour only in the electronic version)

\section{Introduction}

Cement is probably one of the most important materials in human activities. Anhydrous Portland cement is a complex matrix mainly constituted by four phases: tri-calcium silicate, $\mathrm{Ca}_{3} \mathrm{SiO}_{5}$, di-calcium silicate, $\mathrm{Ca}_{2} \mathrm{SiO}_{4}$, tri-calcium aluminate, $\mathrm{Ca}_{3} \mathrm{Al}_{2} \mathrm{O}_{6}$, and tetra-calcium iron aluminate, $\mathrm{Ca}_{4} \mathrm{Al}_{2} \mathrm{Fe}_{2} \mathrm{O}_{10} \cdot{ }^{4}$ The key mechanism of the setting and hardening process is the hydration of these anhydrous phases to give the correspondent hydrated species, responsible for the development of the mechanical and rheological properties of the final cured pastes. Calcium silicates $\left(\mathrm{C}_{3} \mathrm{SeC}_{2} \mathrm{~S}\right)$ react with water to give the calcium silicate hydrate, $\mathrm{CSH}$, an amorphous gel [1] and hexagonal calcium hydroxide, $\mathrm{CH}$, usually referred to as portlandite. The hydration reaction of $\mathrm{C}_{3} \mathrm{~S}$ is completed after one month, while $\mathrm{C}_{2} \mathrm{~S}$ reacts more slowly, taking more than a year to reach completeness. $\mathrm{C}_{3} \mathrm{~A}$ and $\mathrm{C}_{4} \mathrm{AF}$ react with water to give several metastable phases that successively convert in a cubic structure, represented as $\mathrm{C}_{3}(\mathrm{AF}) \mathrm{H}_{6}$. This overall multiple reaction, oversimplified with the word 'hydration', is a process that proceeds in three main steps. The first is a 'dormant' period, or induction, during which the cement hydration proceeds very slowly. It stops at time $t_{i}$; at this point the hydration shows a dramatic acceleration, with a rapid decrease of the water amount with time (nucleation and growth period). At time $t_{\mathrm{d}}$ a deceleration phase begins and the reaction kinetics is controlled by the diffusion rate of species through the mass of the hardened paste. In a common Portland cement, $\mathrm{C}_{3} \mathrm{~S}$ is generally the major constituent of the dry powder (from $70 \%$ to $80 \%$ of the total weight) and it is often used as a model for the study of the cement setting and hardening processes [2] because of its importance in affecting the final cement paste characteristics.

In modern cement technology several additives have been formulated in order to produce cements with better performances (retarders, plasticizers, cellulosic polymers, etc). Among them superplasticizers (SPs) have greatly contributed to the improvement of 'high-performance concretes' (HPCs). These polymeric compounds confer to concrete pastes high flowability, keeping the water content low, improving the workability and ensuring high mechanical strength, durability and low shrinkage of the hardened composite [3-5]. Before the introduction of these additives, paste workability during the mixing and casting processes was obtained by using high water excess. However, at the end of the hydration process of cement the unreacted water remains trapped inside the cement matrix and, as it evaporates, an undesired increase of porosity is developed, decreasing the composite performances, such as mechanical strength and resistance to 'external agents'. With superplasticizers, cement pastes can be produced with the sufficient amount of water to perform the hydration reaction. As a result, the structure of the composite is more compact and it presents higher durability and resistance. From a chemical

4 According to the widely accepted cement-chemical notation, $\mathrm{CaO}, \mathrm{SiO}_{2}, \mathrm{Al}_{2} \mathrm{O}_{3}, \mathrm{Fe}_{2} \mathrm{O}_{3}, \mathrm{H}_{2} \mathrm{O}$ become $\mathrm{C}, \mathrm{S}, \mathrm{A}, \mathrm{F}$, and $\mathrm{H}$ respectively, and the single phases can be represented briefly as $\mathrm{C}_{3} \mathrm{~S}, \mathrm{C}_{2} \mathrm{~S}, \mathrm{C}_{3} \mathrm{~A}$ and $\mathrm{C}_{4} \mathrm{AF}$. 
point of view, superplasticizers can be classified according to their different chemical structures and performances. Nowadays, among the most used additives are sodium salts of sulfonated melamine-formaldehyde (MSF) co-polymers or sulfonated naphthalene-formaldehyde (NSF) co-polymers. Both compounds permit a reduction of the water excess of about $30 \%$, producing only a limited retardation of the setting and hardening processes. Unfortunately, with these additives there is observed a loss of fluidity in time ('slump loss') that is an undesired effect. The 'last generation' of SPs (namely polyacrylic and polycarboxylic polymers) overcomes the previous limit with a much lower dosage and moreover increases the setting time [6-8]. Despite the large efforts devoted to the understanding of both the cement setting process and the mechanism of superplasticizers [9-12], a detailed comprehension is still at a preliminary stage.

Another important class of compounds used in the cement industry is cellulosic polymers: they have been recently investigated since they consistently change the initial paste properties, allowing the cement to be extruded, and hence opening a new range of perspectives for cement applications [13-19]. Extrusion is a processing technique that confers high performance characteristics to cement materials. It is a 'forming' process in which a highly viscous and plastic-like mixture is forced through a die, a rigid opening of desired cross-section. In the case of cement, the achievement of two conflicting requirements complicates this process: the paste should be fluid enough to allow the mixing and thrusting through the die, and the extruded specimen should be stiff enough to allow the easy handling without any shape change. These two requirements are fulfilled by the addition of polymeric derivatives of cellulose to the paste. Nowadays, there is a growing interest in the use of the extrusion process, as for example in the fibre-reinforced cement composites industry. Despite the evident importance of such knowledge for the extrusion technique development, the interaction of cellulose compounds with cement and their contribution to the hydration reaction are far from being clarified [13, 14].

Several techniques can be used to follow the cement hydration reaction and characterize the additive effect on it. In recent years, several experiments have demonstrated the advantages of using neutron scattering to directly access and follow both the hydration kinetics and the water dynamics in a cement paste. The benefits of using neutrons reside in the fact that such a probe is not invasive, not destructive, and directly accesses the translational dynamics of the hydrogenated species (i.e. non-hydrogenated species are almost transparent) [20-22].

Other techniques suitable for the determination of the cement hydration kinetics are for example DSC, NIR and NMR. All these, compared to QENS, are widely available at laboratory and industrial scales, especially DSC and NIR, so that they have been cross-validated through QENS results [23, 24] and applied to the investigation of the industrial additive effect on the thermodynamics of the hydration process. In fact, all techniques access a quantity that is proportional to the degree of reaction (i.e. fraction of immobile water or fraction of reacted water).

As an example, by DSC we determined the Free Water Index parameter, FWI, from the amount of water that can solidify and melt, the so-called freezable water. The fraction of reacted $\mathrm{C}_{3} \mathrm{~S}, \alpha$, can be calculated from the DSC curves of freezable water melting, $\alpha$ being inversely proportional to the experimental enthalpy of fusion of freezable water present in the $\mathrm{C}_{3} \mathrm{~S} /$ water paste. From the FWI, the kinetic mechanism of the cement hydration process has been obtained and compared between samples hydrated with or without additive in order to extract several indicators on the additive action mechanism directly from the hydration thermodynamics [25].

Near-infrared spectroscopy (NIR) was also used to obtain further information on the state of water constrained in a cementitious porous matrix, and, in particular, in tri-calcium silicate, $\mathrm{C}_{3} \mathrm{~S}$, through the examination of the low harmonic modes of stretching and bending of $\mathrm{O}-\mathrm{H}$ bonds. As a matter of fact, the absorption bands in the near-infrared region are known to be 
excellent markers of the state of water $\mathrm{O}-\mathrm{H}$ bonds, since both the strength and the geometry of these bonds affect the frequency of the absorption peaks.

Finally, wide angle $\mathrm{x}$-ray diffraction (WAXD) was applied in order to verify any change on the microstructure of main phases and hydrated crystalline products; ultra small angle neutron scattering (USANS) and scanning electron microscopy (SEM) were used to investigate the morphological change of the anhydrous and hydrated phases upon additive addition.

\section{Experimental section}

Synthetic tri-calcium silicate $\left(\mathrm{C}_{3} \mathrm{~S}\right)$, di-calcium silicate $\left(\mathrm{C}_{2} \mathrm{~S}\right)$, tri-calcium aluminate $\left(\mathrm{C}_{3} \mathrm{~A}\right)$ and tetra-calcium iron aluminate $\left(\mathrm{C}_{4} \mathrm{AF}\right)$ were supplied as a gift by $\mathrm{CTG}$, Italcementi Group, with specific surface area, measured according to the Brunauer-Emmett-Teller theory, of $0.44 \pm 0.05,0.60 \pm 0.05,0.48 \pm 0.05$ and $0.54 \pm 0.05 \mathrm{~m}^{2} \mathrm{~g}^{-1}$ and particle median radius of $6.0,11.0,16.4$ and $12.4 \mu \mathrm{m}$, respectively.

We examined a variety of superplasticizing compounds, belonging to the main available chemical classes. In particular, we dealt with sodium salts of sulfonated naphthalene-formaldehyde polycondensates (NSF, NSF47), polycarboxylates (like HSP114) and polyacrylates (like HSP111), all obtained from CTG, Italcementi. $10 \mathrm{~g} \mathrm{l}^{-1}$ superplasticizer water solutions were prepared.

Methyl hydroxyethyl cellulose was obtained from Hercules with the commercial name Culminal C4045, product type MHEC 40000 PF. A 2\% aqueous solution of Culminal C4045 at $20^{\circ} \mathrm{C}$ has a viscosity of approximately $40000 \mathrm{mPa}$. Water was purified by a Millipore Organex system $(R \geqslant 18 \mathrm{M} \Omega \mathrm{cm})$. Cellulose-added samples were studied with two different formulations, respectively containing $0.2 \%$ and $2.5 \%$ of cellulosic polymer on $\mathrm{C}_{3} \mathrm{~S}$ weight.

DSC measurements were performed using a TA Instruments calorimeter Series Q1000, connected with a personal computer; data were elaborated with Universal Analysis Q series software, version 3.0.3. Measurements were repeated until the end of the hydration kinetics of each sample. Each measurement was carried out with the following temperature program: equilibrate to $-30^{\circ} \mathrm{C}$, hold for $1 \mathrm{~min}$, heat from -30 to $-12{ }^{\circ} \mathrm{C}$ at $20^{\circ} \mathrm{C} \mathrm{min}-1$, from $-12^{\circ} \mathrm{C}$ to $+25^{\circ} \mathrm{C}$ at $4{ }^{\circ} \mathrm{C} \min ^{-1}$. The isothermal step at $-30^{\circ} \mathrm{C}$ was performed to ensure that the free water froze despite supercooling effects.

SEM observations were carried out by means of a Cambridge Stereoscan 360S, working at 8-10 kV of acceleration potential. The electron contrast was enhanced by coating the samples with a gold film by an Agar automatic sputter coater apparatus.

Near-infrared spectra were acquired in the wavenumber interval $7600-4000 \mathrm{~cm}^{-1}$, with a Nexus 870-FTIR (Thermo-Nicolet), in reflectance mode (beamsplitter: KBr; detector: MCT/A) with a resolution of $4 \mathrm{~cm}^{-1}$, co-adding 512 scans. In order to take into account the small part of the incident light transmitted by the sample, the single beam spectra obtained were processed with a reference gold background using the Kubelka-Munk algorithm.

The NMR experimental measurements were performed with a Bruker Biospec ${ }^{\circledR}$ BMT 70/15 equipped with an AVANCE ${ }^{\mathrm{TM}}$ digital spectrometer. A superconducting horizontal magnet generating a $7.05 \mathrm{~T}$ static field $H_{0}$ in a cylindrical region, $20 \mathrm{~cm}$ in length and $15 \mathrm{~cm}$ in diameter, was employed. A birdcage radio-frequency coil of $15 \mathrm{~cm}$ diameter, $60 \mathrm{~cm}$ length, and tuned to $300 \mathrm{MHz}$ for the ${ }^{1} \mathrm{H}$ resonance was used to irradiate the samples. The sample container consists of a cylindrical volume with diameter $6 \mathrm{~cm}$ and length $6 \mathrm{~cm}$. Proton spin-lattice $\left(T_{1}\right)$ relaxation times were determined by using an inversion recovery (IR) sequence [26]. A $180^{\circ}$ radio-frequency pulse was applied for the inversion of the whole magnetization, followed by a $90^{\circ}$ pulse for signal detection. $T_{2}$ relaxation time values were thus acquired by a standard CPMG pulse sequence [26]. All experiments were performed at room temperature $\left(20^{\circ} \mathrm{C}\right)$. 
QENS experiments were carried out mainly using the Disk Chopper Spectromenter at NIST Center for High Resolution Neutron Scattering (CHRNS, Gaithersburg, MD) and the MIBEMOL Spectrometer at LLB (Saclay, Paris). The incident monochromatic neutron wavelength was $9.0 \AA$ (1.01 meV), which resulted in an overall energy resolution (FWHM) of about 20-30 $\mu \mathrm{eV}$. The aluminium sample cell was placed at $45^{\circ}$ to the direction of the incident neutron beam. The detectors were grouped to obtain a set of five spectra in the $Q$ range from 0.31 to $1.22 \AA^{-1}$. The data were corrected for scattering from the same sample holder containing dry calcium silicate or aluminate powder and standardized by dividing by the scattering intensity from a thin vanadium plate (which gives the energy resolution function $R(\omega))$ and converted to the double differential scattering cross-section.

The USANS spectra were collected using the Center for High Resolution Neutron Scattering (CHRNS) perfect crystal diffractometer. Diffraction from a silicon (220) analyser crystal using $2.4 \AA$ neutrons produces high $q$-resolution in one direction. The instrument is described by Drews et al [27]. Each sample scan required $16 \mathrm{~h}$ to complete. The slit-smeared data were corrected for background and put in absolute units by measuring the beam intensity as explained by Schwahn [28]. The data were slit desmeared by a linear method [29].

The WAXD experiment was carried out on the X27C beam-line at the National Synchrotron Light Source, Brookhaven National Laboratory. The wavelength of the X-ray beam was $1.336 \AA$ even though the $2 \theta$-values reported in figures are converted to $\mathrm{Cu} \mathrm{K} \alpha$ (1.542 $\AA$ ). Cement hydration was followed at room temperature. The pastes had a water/cement ratio of 0.5 and a $0.5 \%$ additive concentration (w/w of $\mathrm{C}_{3} \mathrm{~S}$ dry powder). In this case two polynaphthalenesulfonate derivatives (NSF and NSF47) and a polyacrylic (HSP111) additive were studied.

The preparation of the samples for each experimental technique has already been described elsewhere: QENS [20-22, 30-33], DSC [23, 25, 34], NMR [24, 35] and NIR [36].

\section{Results and discussion}

\subsection{State and dynamics of the water phase}

It has been proven [20-22, 30, 32, 33] that the water dynamics in calcium silicate and aluminate pastes can be described with a simple model where at a given time only two categories of water molecules (or hydrogenated molecular species) are considered: a fraction $p$ of immobile water bound inside the hydrated products, and a fraction $1-p$ of glassy water imbedded in the amorphous gel region surrounding the hydrated products. According to this view, the translational part of the intermediate scattering function (ISF) of the water molecule in a cement paste can be written as

$$
F_{s}(Q, t)=p+(1-p) F_{v}(Q, t) \exp \left[-(t / \tau)^{\beta}\right]
$$

where the factor $F_{v}(Q, t) \exp \left[-(t / \tau)^{\beta}\right]$ is the relaxation function of the glassy water according to the 'relaxing-cage model' previously given for supercooled water [37] and hydration water in Vycor glass [38]. In fact, in the low $Q$-range covered in this QENS experiment, it is reasonable to neglect the rotational contribution coming from the water since it becomes relevant only for $Q$ bigger than $1 \AA^{-1}$ [30]. Moreover, $F_{v}(Q, t)$ is demonstrated to be very close to unity for the time range covered in these experiments so that the ISF for the mobile water reduces only to the exponential term weighted by $(1-p)$. The relaxing-cage model treats the short time dynamics of glassy water as vibrations of the centre-of-mass of a typical water molecule in an ensemble of harmonic wells resulting from the cage effect. The long time dynamic of the water molecule follows the relaxation of the cage and is described by the ' $\alpha$-relaxation' process (the stretched exponential factor) suggested by the 'mode coupling theory' $[39,40]$. 

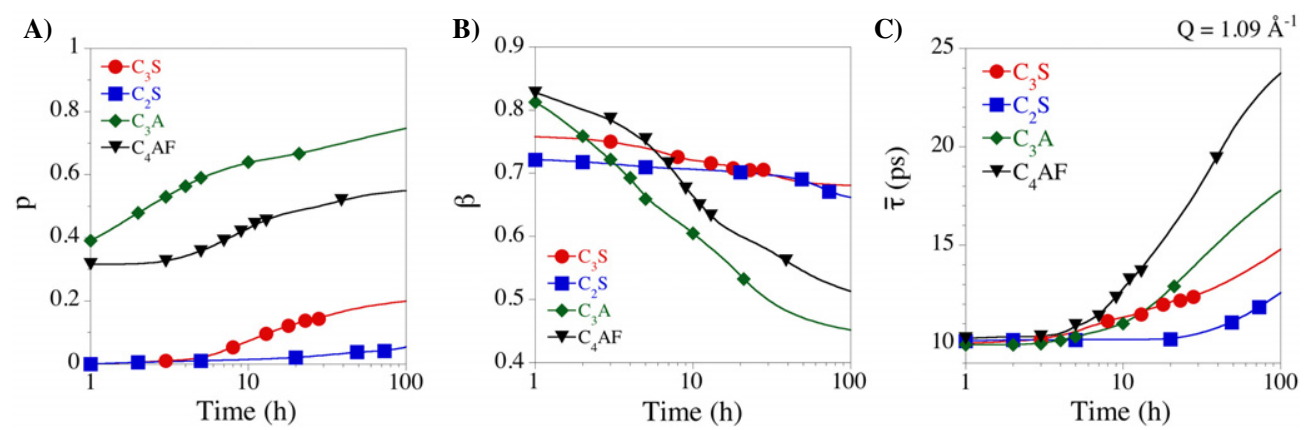

Figure 1. Time evolution of the QENS fitted parameters in the case of the four phases forming an ordinary cement powder $\left(\mathrm{C}_{3} \mathrm{~S}, \boldsymbol{\ominus}, \mathrm{C}_{2} \mathrm{~S}, \boldsymbol{\square}, \mathrm{C}_{3} \mathrm{~A}, \boldsymbol{\vee}, \mathrm{C}_{4} \mathrm{AF}, \boldsymbol{\nabla}\right)$ : (A) bound water $(p)$, (B) stretch exponent, $\beta$ and (C) average relaxation time, $\bar{\tau}$, at $25^{\circ} \mathrm{C}$.

To take into account the immobile water contribution, we added a constant term $p$ to the ISF. According to this approach, the measured spectral intensity, normalized to unity, is fitted using the Fourier transform of equation (1) and convoluted with the experimental resolution function, $R(\omega)$, to give the dynamic structure factor:

$$
S(Q, \omega)=p R(\omega)+(1-p) \Im\left\{\exp \left[-(t / \tau)^{\beta}\right]\right\} \otimes R(\omega)
$$

where $\Im$ represents the Fourier transform and $\otimes$ the convolution operator. In practice, the Fourier transform was carried out numerically since the analytical form of it does not exist. It is worth mentioning that an analytical approach based on the susceptibility function can be successfully applied if the elastic component is not dominant in comparison to the stretched exponential term $[22,33]$. This statement was proved to be consistent with the numerical analysis [41].

Figure 1(a) shows the evolution of the immobile water fraction, $p$, for all the investigated phases. This parameter is directly connected to the reaction degree and permits one to follow the hydration kinetics of the cement paste, especially for $\mathrm{C}_{3} \mathrm{~S}$. As already reported [20, 22], $p$ is $Q$-independent in the investigated $Q$-range. The two calcium aluminates react differently, the $\mathrm{C}_{4} \mathrm{AF}$ phase being slower than the $\mathrm{C}_{3} \mathrm{~A}$ phase. The fraction of reacted water is already around $30 \%$ for $\mathrm{C}_{4} \mathrm{AF}$ and around $40 \%$ for $\mathrm{C}_{3} \mathrm{~A}$ just after $1 \mathrm{~h}$ from the mixing time, showing that the induction time is in the time scale of a few minutes, i.e. it is not accessible by using this technique. Figure 1(b) shows the $\beta$ evolution for the four investigated cases. The $\beta$-value decreases as time passes, showing that the confining properties of the matrix increase in time (i.e. the pore sizes decrease). In particular, for $\mathrm{C}_{3} \mathrm{~A}$ the effect is more marked, probably because a smaller pore size is developed in respect to all other cases. Figure 1(c) illustrates the evolution of the average relaxation time, $\bar{\tau}$, at $Q=1.09 \AA^{-1}$, defined as $\bar{\tau}=(\tau / \beta) \Gamma(1 / \beta)$ [42], where $\Gamma$ is the well-known gamma function. The initial average relaxation time (about $10 \mathrm{ps}$ ) is in all cases more than two times the relaxation time for bulk water at the same temperature and $Q$-value. As the curing time increases the average relaxation time increases since the pore size decreases as long as the reaction takes place.

The previously described neutron scattering technique was compared with the results obtained by DSC. As a matter of fact our innovative DSC method allowed acquiring the whole hydration kinetics of a hydrating paste by using a more industrially accessible technique.

The FWI parameter was calculated from the following formula:

$$
\mathrm{FWI}=\Delta H_{\exp } /\left(x_{\mathrm{H}_{2} \mathrm{O}} \Delta H_{\text {init }}\right)
$$


where $\Delta H_{\text {exp }}$ is the enthalpy change (in $\mathrm{J}$ per $\mathrm{g}$ of $\mathrm{C}_{3} \mathrm{~S} /$ water paste) of the water melting determined by the DSC experimental curve, $x_{\mathrm{H}_{2} \mathrm{O}}$ is the average weight fraction of water in the $\mathrm{C}_{3} \mathrm{~S} /$ water paste, and $\Delta H_{\text {init }}$ is the theoretical value of the specific enthalpy of fusion of water at $0{ }^{\circ} \mathrm{C}$ in the $\mathrm{C}_{3} \mathrm{~S}$ /water paste determined considering that at the beginning of the hydration reaction FWI $=1$. The FWI data obtained by this method were plotted as a function of hydration time. As expected, the curve profiles are characterized by three main stages (see for example figure 4). Considering the stoichiometry of the cement hydration as reported by Fuji and Kondo [43], a simple expression for $\alpha$ as a function of FWI has been reported [44]:

$$
\alpha=3.26(1-\mathrm{FWI})(\mathrm{w} / \mathrm{c}) .
$$

We tested many kinetic equations relative to solid-state reactions [45] and we found that the Avrami model accounts very well for the acceleratory stage. The Avrami law is an extremely simple approximation proposed almost sixty years ago, able to describe homogeneous and heterogeneous nucleation processes. This law is widely used to analyse metastable decay in different fields, ranging from metallurgy to food science, and it provides a wealth of physical information [46]. Garrault et al [47] erroneously considered the Avrami law as formulated for a homogeneous process and suggested a different and quite complex approach to investigate the $\mathrm{CSH}$ formation. This model, although interesting, is not of general use since it provides only the thickness of the $\mathrm{CSH}$ layer on the $\mathrm{C}_{3} \mathrm{~S}$ particle without any information on the energetics associated to the setting process.

The basic Avrami-Erofeev [48-50] equation is

$$
\alpha=1+\alpha_{i}-\exp \left[-k\left(t-t_{i}\right)^{M}\right]
$$

where $\alpha_{i}$ is the fraction of $\mathrm{C}_{3} \mathrm{~S}$ reacted at $t_{i}, k$ is the rate constant, and $M$ is the exponent associated with the nucleation type (dimensionality of the product phase, type of growth, nucleation rate).

Each sample formulation was monitored during the whole kinetics at four different temperatures: $10,20,30$ and $40^{\circ} \mathrm{C}$. Since the $t_{i}$-values are reported to follow an Arrheniustype behaviour, as a function of temperature, $t_{i}^{-1}=t_{0}^{-1} \exp \left(-E_{i} / R T\right)$ [51], it was possible to calculate the activation energy for the induction period. Furthermore, by simply applying the Arrhenius equation,

$$
\ln k_{A-E}=\ln A-E_{A-E} / R T,
$$

the activation energy $E_{A-E}$ for the acceleration period can be easily obtained. The $M$ parameter, obtained from the Avrami fitting, is related to the morphological characteristics of the growing crystals through the following relation [23, 44]:

$$
M=(P / S)+Q
$$

where $P$ can be equal to 1,2 , or 3 corresponding to the growth of fibres, sheets, or polyhedral forms, respectively; $S$ can be equal to 1 or 2 corresponding to phase boundary growth or to diffusion of the reacting species through a liquid phase; and finally $Q$ equal to 0 means no nucleation dependence, whereas $Q$ equal to 1 indicates a constant nucleation.

When all the external part of $\mathrm{C}_{3} \mathrm{~S}$ particles has reacted and $\mathrm{CSH}$ can no longer be formed on the surface, the hydration continues towards the interior of the grains. In these conditions the reaction rate is controlled by the diffusion of species across the gel phase. The relation between degree of reaction (expressed in terms of FWI) and time is the following [43, 44, 51]:

$$
\mathrm{FWI}^{1 / 3}=-\left(2 K_{\mathrm{d}}\right)^{1 / 2}\left(t-t_{\mathrm{d}}\right)^{1 / 2} / R+\left(\mathrm{FWI}_{\mathrm{d}}\right)^{1 / 3}
$$

where $K_{\mathrm{d}}$ is the diffusional constant, $t_{\mathrm{d}}$ the initial time of diffusional period, $\mathrm{FWI}_{\mathrm{d}}$ is the FWI relative to $t_{\mathrm{d}}$ and $R$ is the particle radius. For each curve, data with time greater than $t_{\mathrm{d}}$ were considered to follow the previous law. 

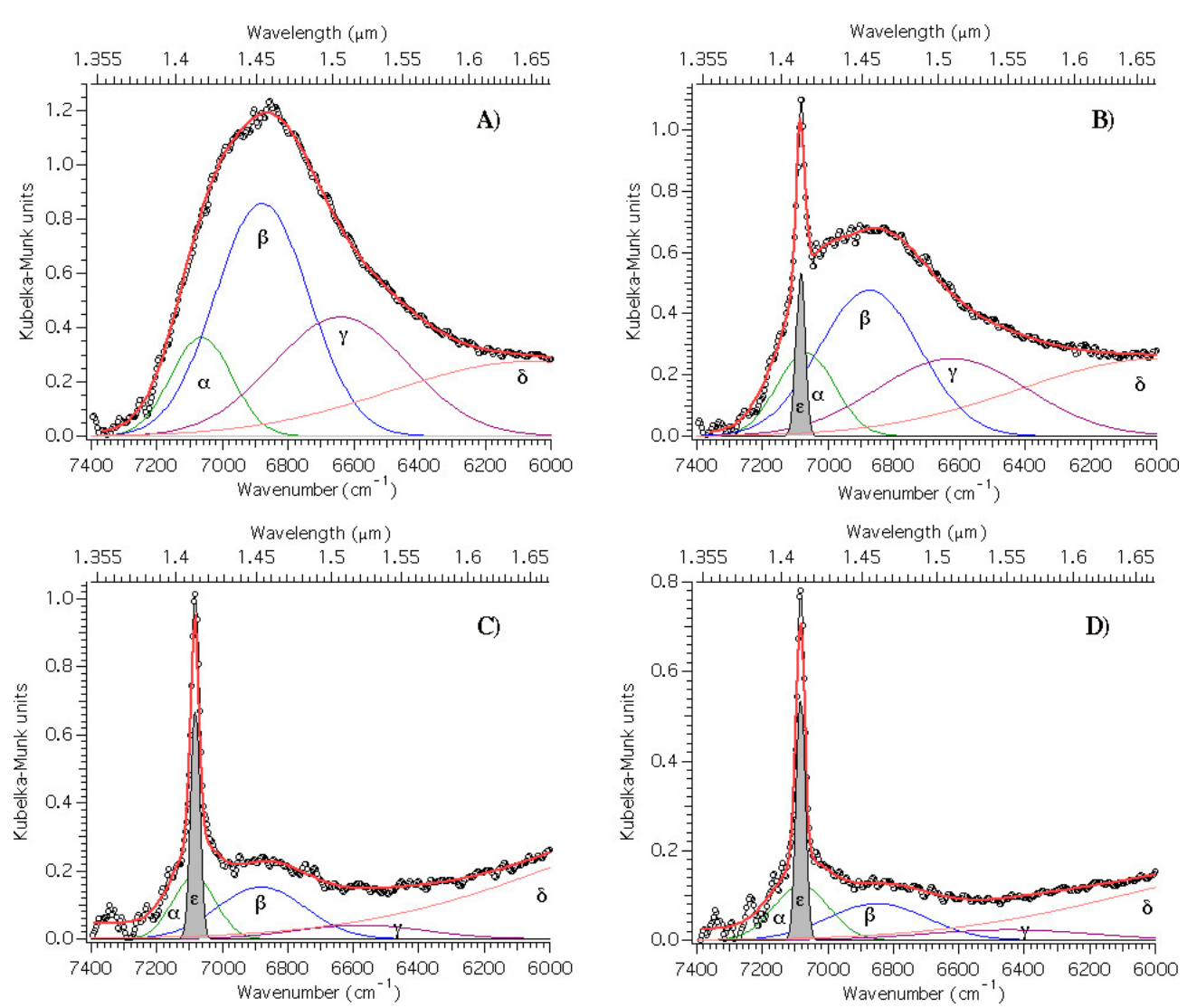

Figure 2. NIR spectra $\left(7400-6000 \mathrm{~cm}^{-1}\right)$ registered at increasing hydration times for the $\mathrm{C}_{3} \mathrm{~S} /$ water paste $(\mathrm{w} / \mathrm{c}=0.4)$ : (A) $3 \mathrm{~h}$, (B) 1 day $(25 \mathrm{~h}),(\mathrm{C}) 19$ days $(456 \mathrm{~h})$, (D) 27 days $(648 \mathrm{~h})$ after mixing.

The state of the water constrained in a tri-calcium silicate investigated through the kinetic of the hydration process was further investigated as a function of time by means of NIR spectroscopy. The spectrum registered three hours from the mixing and corrected for the baseline [24] is dominated by the spectroscopic features of the liquid water (because at this time the water inside the paste has not reacted yet with the anhydrous powder), with two broad bands approximately at 7000 and $5000 \mathrm{~cm}^{-1}$, assigned respectively to the first $\mathrm{O}-\mathrm{H}$ stretching overtone of the water $\left(2 v_{1}, 2 v_{3}, v_{1}+v_{3}\right)$ and to the $\mathrm{O}-\mathrm{H}$ combination band $\left(v_{2}+v_{3}\right)$. During hydration, the total intensity of these two bands decreases, because of the conversion of the water into hydrated phases. Contextually the intensity of the sharp peak at $7083 \mathrm{~cm}^{-1}$, due to the first O-H stretching overtone of portlandite [52], increases.

At each hydration time, the $7000 \mathrm{~cm}^{-1}$ band can be modelled in terms of Gaussian components in order to extract additional information on the states of unreacted water as already described in the literature for other systems [53]. Some of the Gaussian de-convolutions obtained are shown in figure 2. Five Gaussian functions $(\alpha, \beta, \gamma, \delta$ and $\varepsilon$ ) were employed to fit the experimental data. In particular, the fifth Gaussian, $\varepsilon$, was used to account for the very sharp peak at $7083 \mathrm{~cm}^{-1}$ coming from the overtone of the $\mathrm{O}-\mathrm{H}$ stretching in $\mathrm{Ca}(\mathrm{OH})_{2}$ [52]. The $\beta$ and $\gamma$ Gaussians, respectively at 6600 and $6900 \mathrm{~cm}^{-1}$, are attributed to a continuum of strongly hydrogen bonded water molecules rather than to specific molecular classes [53], 


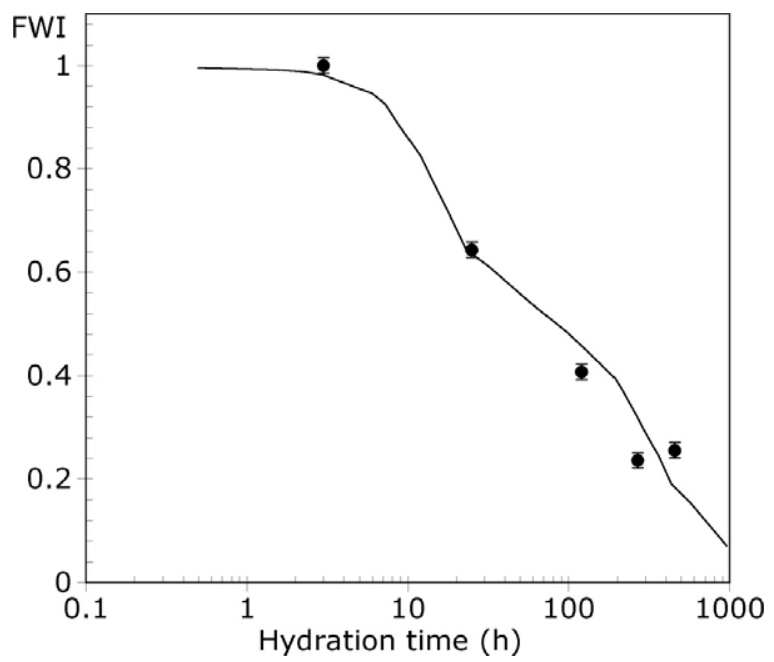

Figure 3. Comparison between the FWI as obtained from calorimetric measurement (continuous line) and the FWI obtained from the areas of the NIR band at $5000 \mathrm{~cm}^{-1}(\mathbf{)})$, normalized to unity.

while $\alpha$ (around $7070 \mathrm{~cm}^{-1}$ ), is attributed to the oscillation of weak $\mathrm{O}-\mathrm{H}$ bonds (i.e. water molecules bonded to the surface). It is well reported in the literature that both the temperature increase [54] and geometric constrains imposed on the water phase [53] produce an increment of the 'weakly hydrogen bonded' population intensity. Finally, the $\delta$ component is used to take into account the background contribution coming from the $\mathrm{KBr}$ beamsplitter.

In the literature the combination band at $\sim 5000 \mathrm{~cm}^{-1}$ has been used in a quantitative way for the determination of total amount of water present in the sample $[55,56]$. The comparison between the FWI versus time, as obtained with DSC [25], and the overall area of the $\sim 5000 \mathrm{~cm}^{-1}$ band, normalized to the area registered at the beginning of the hydration process (figure 3),

$$
\mathrm{FWI}_{\mathrm{NIR}}(t)=\frac{A_{5000}(t)}{A_{5000}(t=0)}
$$

shows an excellent agreement between the NIR and the DSC approach. Therefore, the area of the $5000 \mathrm{~cm}^{-1}$ combination band can successfully monitor the hydration kinetics.

The areas of $\alpha, \beta$ and $\gamma$, normalized to the $5000 \mathrm{~cm}^{-1}$ band, were determined and their time evolution (data not shown) [24] evidences that the $\beta$ and $\gamma$ contributions decrease in time, while $\alpha$ increases. This can be ascribed to the development of the CSH surface, i.e. the percentage of 'surface-interacting' water becomes preponderant over the 'bulk water' fraction. This is in agreement with the analysis of the $\alpha$ peak position, showing a progressive increase of its wavenumber, from $7065 \pm 4$ to $7082 \pm 4 \mathrm{~cm}^{-1}$. In fact, a value of $7066 \pm 3 \mathrm{~cm}^{-1}$ is reported for the $\alpha$ component in bulk water, while $7088 \pm 2 \mathrm{~cm}^{-1}$ is typical of the same component in a dry silica hydrogel [53]. Furthermore, the comparison between the increase of the surface-interacting water in the sample and the ratio of the surface area to weight of dry $\mathrm{C}_{3} \mathrm{~S}$ (as determined from the surface to volume ratio, obtained from NMR spin-spin relaxation data) clearly evidenced that the two quantities have the same trend [24]. We can conclude that the proposed Gaussian deconvolution approach clearly allows the quantification of the evolution of the surface interacting water, this quantity being directly connected to the surface formation of the hydrated products. 


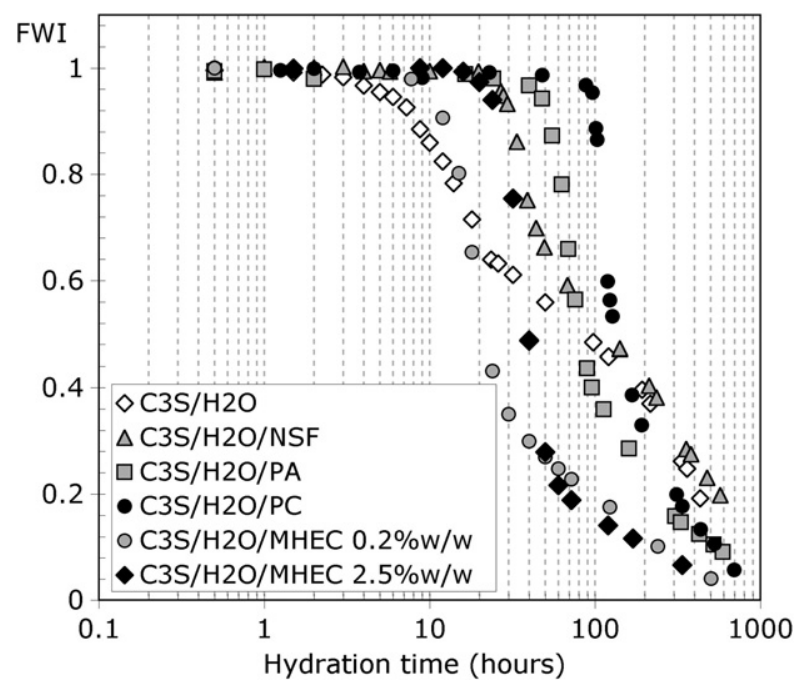

Figure 4. Hydration kinetics of tri-calcium silicate hydrated with pure water, with SPs (naphthalene sulphonic, polyacrylate, polycarboxylate) and with methyl hydroxy ethyl cellulose at $0.2 \%$ and $2.5 \% \mathrm{w} / \mathrm{w}$ on $\mathrm{C}_{3} \mathrm{~S}$ weight.

\subsection{Additives effect on cement hydration}

Figure 4 shows the hydration kinetics of $\mathrm{C}_{3} \mathrm{~S}$ in the presence of additives at $20^{\circ} \mathrm{C}$ for some representative sample compositions. The addition of each organic compound to $\mathrm{C}_{3} \mathrm{~S}$ was tested at $10,20,30$ and $40^{\circ} \mathrm{C}$; the previously described parameters were obtained for the nucleation and growth and the diffusion-limited laws and are reported in table 1 together with the activation energies for the induction and the acceleration period.

Additives produce some interesting modification. The first effect is the delay in the setting of $\mathrm{C}_{3} \mathrm{~S}$ paste. This retardation is generally stronger when a superplasticizer is included in the mixture, while the cellulosic polymer produces a weaker effect, even if the added amount is higher. The maximum increment of $t_{i}$ and of $t_{d}$ (and therefore the delay in the setting) is induced by the PC (HSP114), followed by PA (HSP111), NSF, MHEC 2.5\% and MHEC 0.2\% $(\mathrm{w} / \mathrm{w})$. The second important modification of the process is that in the presence of additives the end of the nucleation and growth period corresponds to lower values of FWI (0.2-0.4) than 0.6 found in the case of pure water; this reflects an enhanced availability of water inside the paste, so that the hydration of $\mathrm{C}_{3} \mathrm{~S}$ is more effective. In particular, in the case of MHEC $2.5 \% \mathrm{w} / \mathrm{w}$, only $26 \%$ (averaged value over the four investigated temperatures) of the initial water remains unreacted at the end of the acceleration period, while for the $\mathrm{C}_{3} \mathrm{~S}$ /water sample this percentage is around $60 \%$ [36].

The activation energies for the induction period, reported in table 1, are comparable for pure water $\left(38 \mathrm{~kJ} \mathrm{~mol}^{-1}\right)$ and the cellulose-added pastes $\left(42\right.$ and $\left.40 \mathrm{~kJ} \mathrm{~mol}^{-1}\right)$. It is worth noting that the increment of cellulose amount does not affect the temperature dependence of the induction times very much. A similar value for $E_{i}$ was obtained for NSF $\left(43 \mathrm{~kJ} \mathrm{~mol}^{-1}\right)$, while for PA and PC the values resulted in being 28 and $29 \mathrm{~kJ} \mathrm{~mol}^{-1}$, respectively. This finding was also present for other additives belonging to the same chemical class, with a temperature dependence from the neat $\mathrm{C}_{3} \mathrm{~S} / \mathrm{H}_{2} \mathrm{O}$ paste even more emphasized [36].

The activation energy for the nucleation and growth period obtained for $\mathrm{C}_{3} \mathrm{~S}$ hydration in pure water $\left(35 \mathrm{~kJ} \mathrm{~mol}^{-1}\right)$ is in good agreement with the literature, where an activation energy 
Table 1. Parameters of the nucleation and growth process and of the diffusional period, for $\mathrm{C}_{3} \mathrm{~S}$ hydration in water with and without superplasticizers.

\begin{tabular}{|c|c|c|c|c|c|c|c|c|c|}
\hline & \multicolumn{4}{|c|}{ Nucleation and growth } & \multicolumn{3}{|c|}{ Diffusion-limited } & \multicolumn{2}{|c|}{ Activation energies } \\
\hline & $\begin{array}{l}T \\
\left({ }^{\circ} \mathrm{C}\right)\end{array}$ & $t_{i}(\mathrm{~h})$ & $k\left(\mathrm{~h}^{-1}\right)$ & $M$ & $t_{\mathrm{d}}(\mathrm{h})$ & $\mathrm{FWI}_{\mathrm{d}}$ & $\begin{array}{l}K_{\mathrm{d}} \times 10^{15} \\
\left(\mathrm{~m}^{2} \mathrm{~h}^{-1}\right)\end{array}$ & $E_{i}\left(\mathrm{~kJ} \mathrm{~mol}^{-1}\right)$ & $E_{A-E}\left(\mathrm{~kJ} \mathrm{~mol}^{-1}\right)$ \\
\hline Water & 10 & 8 & 0.0113 & 1.3 & 38 & 0.45 & 13.7 & \multirow{4}{*}{38} & \multirow{4}{*}{37} \\
\hline Water & 20 & 6 & 0.0234 & 1.1 & 32 & 0.61 & 4.33 & & \\
\hline Water & 30 & 5 & 0.0271 & 1.0 & 18 & 0.68 & 3.72 & & \\
\hline Water & 40 & 1.5 & 0.0579 & 1.1 & 9.5 & 0.69 & 2.99 & & \\
\hline MHEC $2.5 \%$ & 10 & 32 & 0.0024 & 1.6 & 189 & 0.23 & 1.17 & \multirow{4}{*}{42} & \multirow{4}{*}{77} \\
\hline MHEC $2.5 \%$ & 20 & 15 & 0.0087 & 1.7 & 60 & 0.21 & 2.38 & & \\
\hline MHEC $2.5 \%$ & 30 & 8 & 0.0202 & 1.7 & 40 & 0.20 & 2.50 & & \\
\hline MHEC $2.5 \%$ & 40 & 6 & 0.0605 & 1.3 & 18.5 & 0.39 & 2.34 & & \\
\hline MHEC $0.2 \%$ & 10 & 20 & 0.0095 & 1.5 & 50 & 0.33 & & \multirow{3}{*}{40} & \multirow{3}{*}{38} \\
\hline MHEC $0.2 \%$ & 20 & 12 & 0.0334 & 1.4 & 30 & 0.35 & 4.89 & & \\
\hline MHEC $0.2 \%$ & 40 & 4 & 0.0511 & 1.6 & 11 & 0.48 & 6.48 & & \\
\hline NSF & 10 & 78.5 & 0.0025 & 1.6 & 126 & 0.50 & 3.77 & \multirow{4}{*}{43} & \multirow{4}{*}{65} \\
\hline NSF & 20 & 27 & 0.0067 & 1.4 & 49.5 & 0.66 & 3.62 & & \\
\hline NSF & 30 & 26 & 0.0243 & 1.0 & 47.5 & 0.73 & 3.72 & & \\
\hline NSF & 40 & 11.5 & 0.0563 & 0.7 & 18 & 0.57 & 2.90 & & \\
\hline $\mathrm{PA}$ & 10 & 107 & 0.0025 & 1.6 & 168 & 0.29 & 8.11 & \multirow{4}{*}{28} & \multirow{4}{*}{78} \\
\hline $\mathrm{PA}$ & 20 & 48 & 0.0067 & 1.4 & 96 & 0.40 & 3.82 & & \\
\hline PA & 30 & 41.5 & 0.0243 & 1 & 89.25 & 0.48 & 6.66 & & \\
\hline PA & 40 & 32 & 0.0563 & 0.7 & 87 & 0.51 & 3.57 & & \\
\hline PC & 10 & 192 & 0.0045 & 1.5 & 288.5 & 0.28 & 4.89 & \multirow{4}{*}{29} & \multirow{4}{*}{82} \\
\hline $\mathrm{PC}$ & 20 & 96.5 & 0.0136 & 1.2 & 167.25 & 0.39 & 3.72 & & \\
\hline PC & 30 & 68 & 0.0392 & 0.8 & 144.5 & 0.39 & 4.34 & & \\
\hline $\mathrm{PC}$ & 40 & 60 & 0.131 & 0.5 & 96.75 & 0.38 & 3.19 & & \\
\hline
\end{tabular}

interval from 30 to $40 \mathrm{~kJ} \mathrm{~mol}^{-1}$, depending on the particle size distribution, is reported [51, 57]. The activation energy for this process is not modified when a small amount of MHEC is added to the paste; on the contrary, a ten times higher amount of cellulosic polymer causes a consistent increase of the activation energy, probably due to the a large amount of water strictly bound to the polymer. Thermogravimetric analysis has demonstrated that roughly the $23 \%$ of the initially added water is bound to the polymer chain [36]. Also in the presence of superplasticizers the activation energies for the hydration are significantly higher than in pure water. PA and PC give similar results $\left(78-82 \mathrm{~kJ} \mathrm{~mol}^{-1}\right)$, suggesting a similar mechanism, while the NSF has a smaller activation energy $\left(65 \mathrm{~kJ} \mathrm{~mol}^{-1}\right)$.

Table 1 also shows that the average value of $M$ is around unity for $\mathrm{C}_{3} \mathrm{~S}$ mixed with pure water and confirms previous results $[58,59]$. This value of $M$ is consistent with two possibilities: (i) fibres, phase boundary, no nucleation dependence, $(P=1, S=1, Q=0$; also reported in literature as $(1,1,0))$, and (ii) sheets, diffusion, no nucleation dependence, $(P=2, S=2, Q=0 ;(2,2,0))$. The SEM observation confirms that in this system the grain's surface is covered by fibre-like hydrated phase (figures $5(\mathrm{~A})-(\mathrm{C})$ ), as reported in literature, and we can then conclude that the type of growth can be classified as $(1,1,0)$. The $M$ index is around 1.5 in the presence of MHEC and, according to its definition, this modification must be attributed to a change in the hydrated phase's morphology. When superplasticizers are added to the paste, $M$ changes with the temperature, being around 1.6 at $10^{\circ} \mathrm{C}$ and around 0.5 


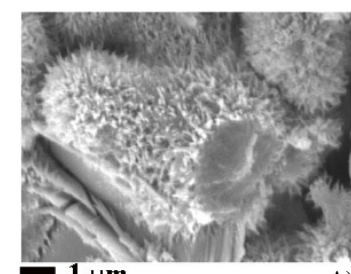

$1 \mu \mathrm{m}$

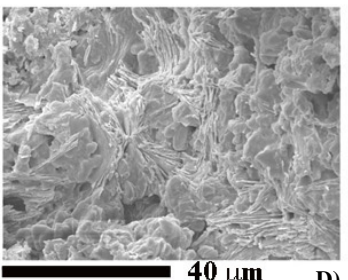

$40 \mu \mathrm{m}$

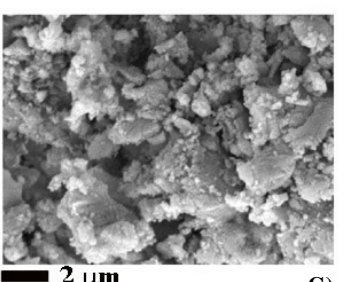

G)

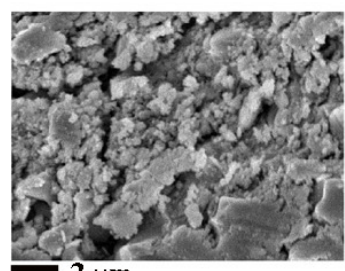

L)

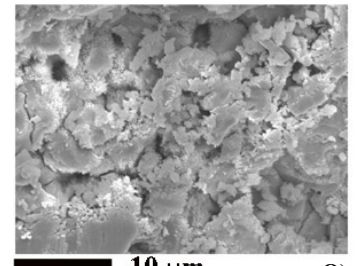

$10 \mu \mathrm{m}$

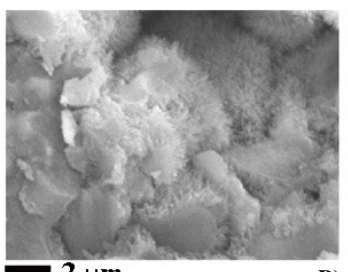

B)
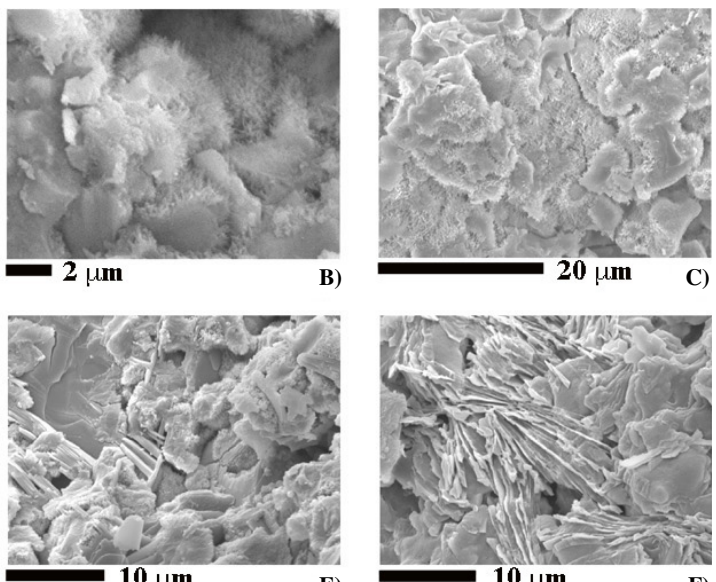

$10 \mu \mathrm{m}$

E)
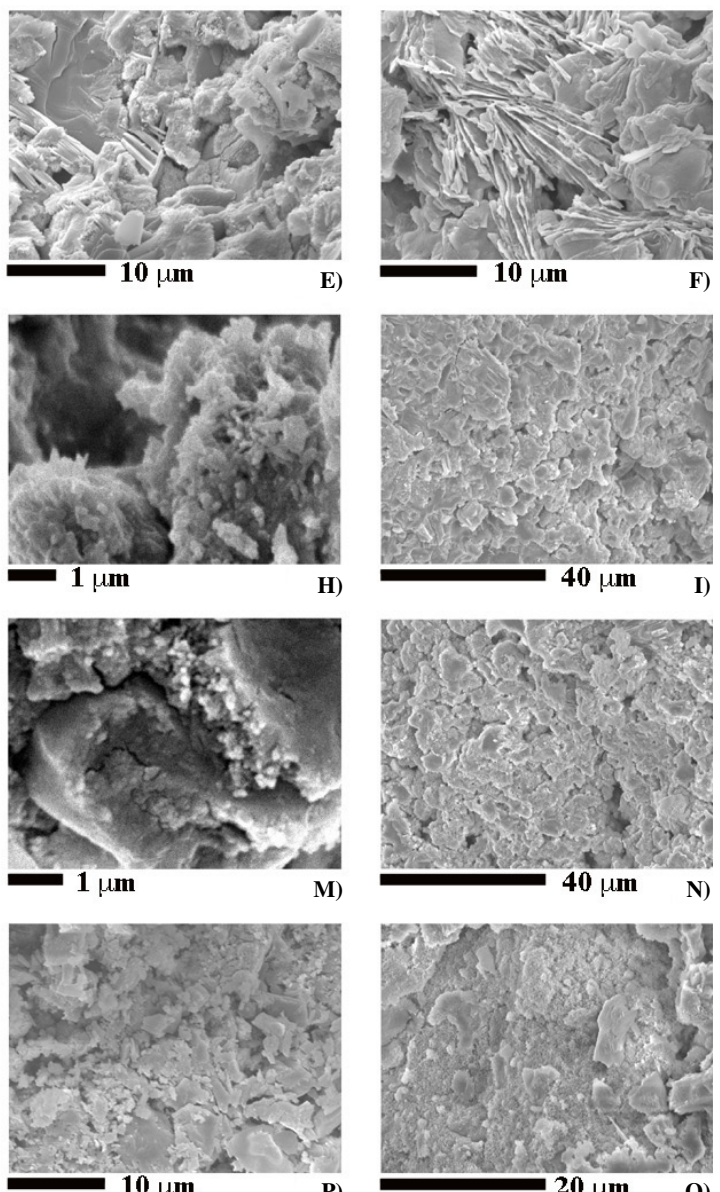

Figure 5. SEM micrographs of fractured $\mathrm{C}_{3} \mathrm{~S}$ pastes $(\mathrm{w} / \mathrm{c}=0.4)$ in pure water at $(\mathrm{A}) 7$ days, $(\mathrm{B})$ 13 days, (C) 1 month of hydration; with MHEC 2.5\% w/w (D) 7 days, (E) 13 days, (F) 1 month of hydration; with NSF (G) 7 days, (H) 13 days, (I) 1 month of hydration; with PA (L) 7 days, (M) 13 days, (N) 1 month of hydration; with PC (O) 7 days, (P) 13 days, (Q) 1 month of hydration.

at $40{ }^{\circ} \mathrm{C}$. The mean value is again 1 , but the SEM investigations (performed both on fractured cured pastes-figures $5(\mathrm{G})-(\mathrm{O})$, and on very diluted suspensions-not shown) $[25,36]$ confirm that the fibrillar structures are not present, also after long incubation periods, while the formation of some other regular structures around the main grains is enhanced. This is consistent with a different type of growth, associated presumably to the growth in solution $(S=2)$ of structures with different morphologies (polygons, $P=3$; sheets, $P=2$; fibrils, $P=1$ ) depending on the curing temperature. Again the $M$-values obtained for the 
cellulose-added pastes reveal a modification in the hydrated phase's morphology, as testified by SEM micrographs (figures 5(D)-(F)).

The diffusional constants obtained for pastes of $\mathrm{C}_{3} \mathrm{~S}$ in pure water are very similar to those reported in a previous work with neutron scattering, with the same w/c ratio and with similar surface area of the powder [51], further confirming the validity of our method. Several studies showed the $K_{\mathrm{d}}$-values to be independent of temperature [23, 51]. This is attributed to the competition between two different contributes, the thermal activation for the diffusional process and the higher density of the gel phase at higher temperatures [23, 51, 60, 61]. The diffusional constants would tend to increase as a function of temperature because of the thermal activation contribution; on the other hand it is demonstrated that at higher temperatures the hydrated matrix is extremely compact, thus reducing the diffusion ability of the molecules across it. In particular, previous studies based on backscattering electron imaging showed that samples cured at high temperature $\left(>40^{\circ} \mathrm{C}\right)$ have a very compact inner $\mathrm{CSH}$, while the outer product is inhomogeneous and porous. Samples cured at low temperature $\left(10-20^{\circ} \mathrm{C}\right)$ are more homogeneous and therefore the diffusion through the hydrated phases is not hindered [60]. The decreasing trend of the $K_{\mathrm{d}}$ observed for $\mathrm{C}_{3} \mathrm{~S}$ pastes hydrated in pure water, as the temperature increase, should indicate that in this case the second contribution is predominant.

When $\mathrm{C}_{3} \mathrm{~S}$ is hydrated in the presence of a superplasticizer any clear trend for diffusional constants is found as a function of temperature, probably due to the fact that the two previous contributions to the diffusion process offset each other. On the other hand a low amount of MHEC $(0.2 \% \mathrm{w} / \mathrm{w})$ has been found to modify the effect of the temperature on the diffusional constants, restoring the thermal activation of the diffusion process [34]; this has been attributed to the controlled release of the water to the anhydrous silicate, avoiding the inhomogeneous growth of the hydrated phases at high temperatures. When the MHEC amount is ten times higher, $K_{\mathrm{d}}$ becomes temperature independent. In this case, the water left after the acceleration period is limited and strictly bound to the MHEC polymer and its diffusion is mainly determined by the interaction with MHEC chains instead of the characteristics of the hydrated phase's morphology.

The nuclear magnetic resonance technique allowed us to monitor the evolution of the rotational mobility of the unreacted water during the hydration process. The longitudinal $\left(T_{1}\right)$ and transversal $\left(T_{2}\right)$ relaxation times were acquired on a $\mathrm{C}_{3} \mathrm{~S}$ hydrating paste with pure water and in the presence of MHEC $0.2 \% \mathrm{w} / \mathrm{w}$ and are reported in figures $6(\mathrm{~A})$ and $(\mathrm{B})$ as a function of time. We observed that the values of $T_{1}$ and $T_{2}$ at the beginning of the kinetics (respectively $1.1 \mathrm{~s}$ and $6 \mathrm{~ms}$ in the sample containing MHEC) are very close to those measured for water in an MHEC/water gel without solid phase $\left(T_{1}=1.23 \mathrm{~s} ; T_{2}=5.75 \mathrm{~ms}\right)$ : this confirms that in cellulose-containing pastes the polymer acts like a 'mediator', controlling the release of the water to the powder. The calorimetric analysis provides further confirmation of this point (as already described). The comparison of the $T_{1}$ versus time plots with the kinetics obtained by calorimetry at the same curing temperature allowed us also to extract interesting information on the mechanism of immobilization of the water inside the paste [35].

Additional in situ information on the growing CSH phase were obtained from ultra small angle neutron scattering, and wide angle x-ray scattering.

Figure 7 shows the USANS/SANS spectra of $\mathrm{C}_{3} \mathrm{~S}$ paste hydrated with $\mathrm{D}_{2} \mathrm{O}$ for 1 day in presence or not of SPs. Three different regions are evident: a Guinier region from 0.00002 to $0.0003 \AA^{-1}$, a Porod region from 0.0003 to $0.02 \AA^{-1}$ and finally a fractal region from 0.02 to $0.2 \AA^{-1}$ where $I(Q)$ scales as $Q^{-D}(D \sim 2.5-2.6)$. Table 2 lists the gyration radius extracted using the Guinier approximation [62]. It is worth noting that in a static neutron scattering experiment the maximum probed dimension is given roughly by $2 \pi / Q_{\min }$; in the present case 

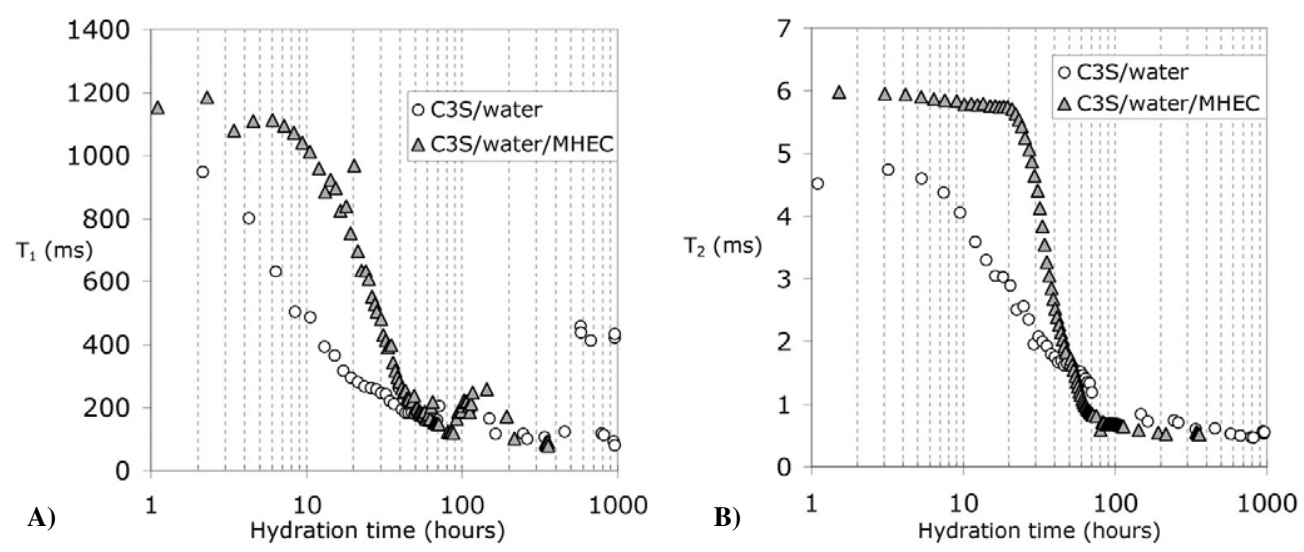

Figure 6. Longitudinal (A) and transversal (B) relaxation time evolutions for $\mathrm{C}_{3} \mathrm{~S}$ pastes hydrating in pure water and in presence of MHEC.

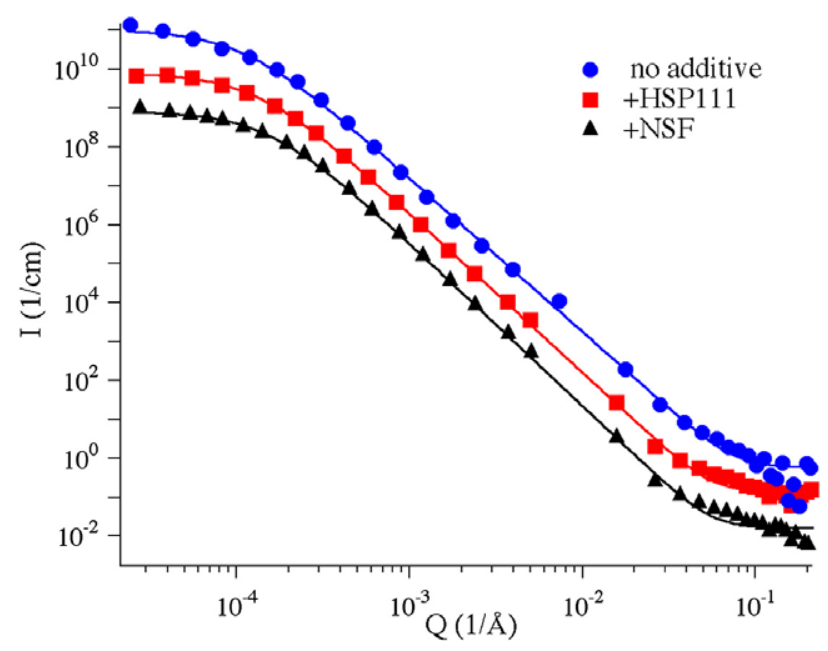

Figure 7. USANS/SANS merged spectra obtained on one day old $\mathrm{C}_{3} \mathrm{~S} / \mathrm{D}_{2} \mathrm{O}$ pastes having a $\mathrm{w} / \mathrm{c}=0.5$ with: no additive, $\mathbf{O}, \mathrm{HSP} 111, \mathbf{\square}$, and NSF, $\boldsymbol{\Delta}$. The continuous lines represent the fitting result obtained using the Sabine power-law approach [63]. The spectra with no additive and HSP111 have been appropriately offset in order to make the view easier.

Table 2. Apparent radius of gyration extracted in the Guinier approximation for a $C_{3} S / D_{2} O$ paste aged for one day with and without SP addition.

\begin{tabular}{ll}
\hline & $R_{g}(\AA)$ \\
\hline Water & $24905 \pm 271$ \\
HSP111 & $16064 \pm 131$ \\
NSF & $14983 \pm 135$ \\
\hline
\end{tabular}

this value is a few microns. For this reason the radius of gyration extracted will be apparent, since some grains are known to have a bigger size. The presence of the additive decreases the grain size. Both the Porod region and the fractal region are less affected. 

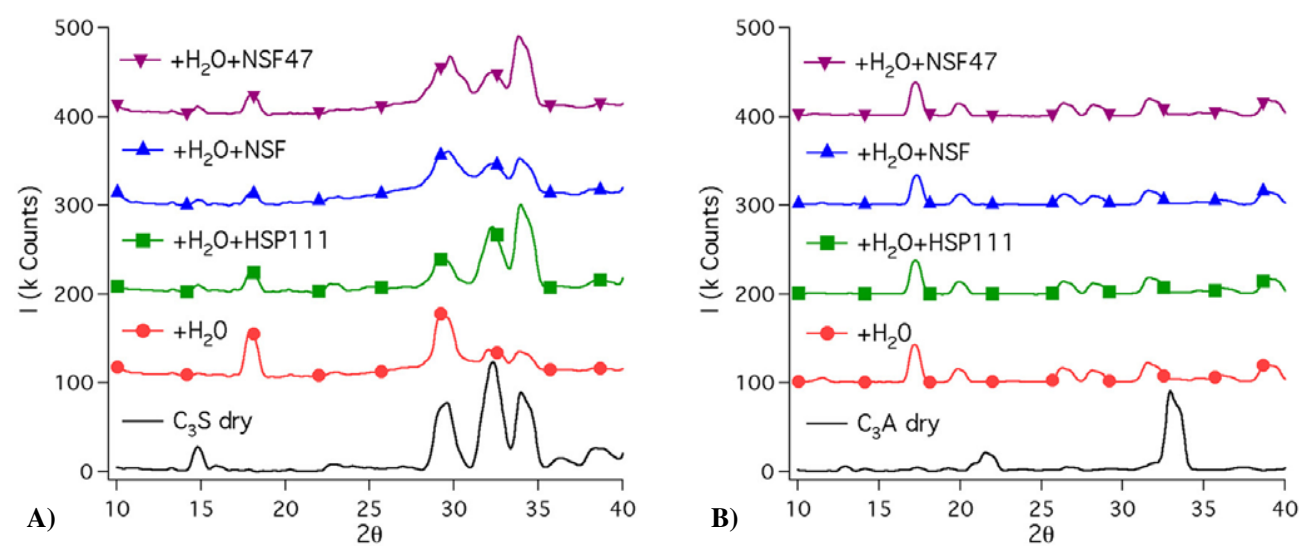

Figure 8. WAXD spectra of different cement pastes: (A) $\mathrm{C}_{3} \mathrm{~S}$ dry powder $\left(\mathrm{C}_{3} \mathrm{~S}\right)$, hydrated $(0.5 \mathrm{w} / \mathrm{c})$ $\mathrm{C}_{3} \mathrm{~S}$ after 18 days $\left(\mathrm{H}_{2} \mathrm{O}\right)$, hydrated $(0.5 \mathrm{w} / \mathrm{c}) \mathrm{C}_{3} \mathrm{~S}$ after 18 days in presence of $0.5 \%$ of different SPs (NSF, NSF47, and HSP). (B) $\mathrm{C}_{3} \mathrm{~A}$ dry powder $\left(\mathrm{C}_{3} \mathrm{~A}\right)$, hydrated $(0.5 \mathrm{w} / \mathrm{c}) \mathrm{C}_{3} \mathrm{~A}$ after 18 days $\left(\mathrm{H}_{2} \mathrm{O}\right)$, hydrated $(0.5 \mathrm{w} / \mathrm{c}) \mathrm{C}_{3} \mathrm{~A}$ after 18 days in presence of $0.5 \%$ of different SPs (NSF, NSF47, and HSP).

Table 3. Parameters extracted by the Sabine power-law approach for a $C_{3} S / D_{2} O$ paste aged for one day with and without SP addition.

\begin{tabular}{llll}
\hline & $\mathrm{H}_{2} \mathrm{O}$ & $\mathrm{HSP} 111$ & $\mathrm{NSF}$ \\
\hline$A$ & $15.0 \times 10^{9}$ & $9.76 \times 10^{8}$ & $8.32 \times 10^{8}$ \\
$R(\AA)$ & 15948 & 13178 & 11209 \\
$C$ & 0.0087 & 0.0162 & 0.0163 \\
\hline
\end{tabular}

A detailed fitting of the three spectra is not the purpose of this paper, but a very simple fit can be made following the Sabine power-law approach [63]:

$$
I(Q)=A /\left(1+\frac{(R Q)^{2}}{3}\right)^{2}+B Q^{-S}+C
$$

where $A$ and $B$ are constants, $R$ is the radius of the quasi-spherical scattering particle (mainly the unreacted grains), $S$ is the power-law exponent (i.e. $S=$ mass fractal dimension or $S=6$ surface fractal dimension) and $C$ is the incoherent background. Any multiple scattering or polydispersity effect is neglected.

As shown by table 3, the decrease in the grain size is confirmed. Moreover, since $B$ resulted in being negligible with respect to $A$, the contribution from the hydrated calcium silicate gel is negligible in USANS/SANS spectra of a $\mathrm{C}_{3} \mathrm{~S} / \mathrm{D}_{2} \mathrm{O}$ paste. This is in complete agreement with Phair et al [64].

USANS shows that SPs reduce the mean dimension of the $\mathrm{C}_{3} \mathrm{~S}$ grains and this effect is still evident after one day. The same effect has been noticed using other techniques (SEM and optical microscopy image analysis). The main contribution can be ascribed to the unreacted grains.

Figure 8 shows the WAXD spectra in the case of $\mathrm{C}_{3} \mathrm{~S}$ powder and $\mathrm{C}_{3} \mathrm{~S}$ after 18 days of hydration with or without SPs. Each peak reported is due to one or more faces in the crystalline structure. The data clearly indicate that additives stop the CSH formation by modulating the lattice face growth. In fact, the peak at $18^{\circ}$, coming from portlandite, increases less in the presence of additives. Furthermore, the peak at about $15^{\circ}$ due to the dry $\mathrm{C}_{3} \mathrm{~S}$ is still present in 
samples containing SPs. The peaks at $29^{\circ}, 32^{\circ}$ and $34^{\circ}$ are characteristic of unreacted $\mathrm{C}_{3} \mathrm{~S}$. As we can see in terms of relative intensities, the faces corresponding to the peaks at $32^{\circ}$ and $34^{\circ}$ are more reactive when no additive is added. Moreover, SPs strongly block reactions occurring at the lattice face related to the peak at $34^{\circ}$. These results clearly suggest that additives have a selective binding to preferential crystal lattice directions of $\mathrm{C}_{3} \mathrm{~S}$. The effect on the other phases (only $\mathrm{C}_{3} \mathrm{~A}$ is reported in figure 8 ) is weaker, suggesting that additives mainly affect $\mathrm{C}_{3} \mathrm{~S}$.

\section{Conclusions}

The setting process of cement can be understood by following the state of the hydration water and the microstructure development of a cement paste. We used several techniques that provide a wealth of information on the dynamics of water molecules in hydrated calcium silicates $\left(\mathrm{C}_{3} \mathrm{~S}, \mathrm{C}_{2} \mathrm{~S}\right)$ and aluminates $\left(\mathrm{C}_{3} \mathrm{~A}, \mathrm{C}_{4} \mathrm{AF}\right)$, such as quasi-elastic neutron scattering, differential scanning calorimetry, and near-infrared spectroscopy. The obtained information allowed understanding of most of the important features of the setting process and, in particular, a quantitative determination of how the additives used most by the cement industry affect the curing process.

\section{Acknowledgments}

The authors thank L Cassar, R Alfani, G Guerrini and M Biagini (CTG-Italcementi Group) and L Dei (CSGI) for invaluable comments and discussions. Financial support from CTGItalcementi Group, Ministero dell' Istruzione, Università e della Ricerca Scientifica, MIUR, and Consorzio Interuniversitario per lo Sviluppo dei Sistemi a Grande Interfase, CSGI, is gratefully acknowledged. Many thanks are due to J Barker for the help with the USANS experimental set-up and data reduction. The USANS data was taken using facilities supported in part by the National Science Foundation under Agreement No DMR-9986442. Finally, we are indebted to B Hsiao and B Chu for helping with the experimental set-up of the X27C beam line. The Brookhaven National Laboratory is gratefully acknowledged for the allocated beam time.

\section{References}

[1] Xu Z and Viehland D 1996 Phys. Rev. Lett. 77 952-5

[2] Livingston R A, Neumann D A, Allen A J and Rush J J 1995 Application of neutron scattering methods to cementitious materials Mater. Res. Soc. Symp. Proc. vol 376, ed D A Neumann, T P Russell and B J Wuensch, pp 459-69

[3] Collepardi M 1998 Cem. Concr. Comput. 20 103-12

[4] Jolicoeur C and Simard M A 1998 Cem. Concr. Comput. 20 87-101

[5] Sakai E and Daimon M 1995 Mater. Sci. Concr. IV 91-111

[6] Hanehara S and Yamada K 1999 Cem. Concr. Res. 29 1159-65

[7] Uchikawa H, Hanehara S, Shirasaka T and Sawaki D 1992 Cem. Concr. Res. 22 1115-29

[8] Uchikawa H, Sawaki D and Hanehara S 1995 Cem. Concr. Res. 25 353-64

[9] Peiwei G, Min D and Naiqian F 2001 Cem. Concr. Res. 31 703-6

[10] Gartner E M 1997 Cem. Concr. Res. 27 665-72

[11] Bezjak A 1986 Cem. Concr. Res. 16 605-9

[12] Krstulovic R and Dabic P 2000 Cem. Concr. Res. 30 693-8

[13] Mishra P C, Singh V K, Narang K K and Singh N K 2003 Mater. Sci. Eng. A 357 13-9

[14] Saric-Coric M, Khayat K H and Tagnit-hamou A 2003 Cem. Concr. Res. 33 1999-2008

[15] Lu Z and Zhou X 2000 Cem. Concr. Res. 30 227-31

[16] Silva D A, John V M, Ribeiro J L D and Roman H R 2001 Cem. Concr. Res. 31 1177-84

[17] Shao Y, Qiu J and Shah S P 2001 Cem. Concr. Res. 31 1153-61 
[18] Klemm A J and Klemm P 1997 Buildings Environment 32 195-8

[19] Klemm A J and Klemm P 1997 Buildings Environment 32 199-202

[20] Fratini E, Chen S H, Baglioni P and Bellissent-Funel M C 2002 J. Phys. Chem. B 106 158-66

[21] Fratini E, Chen S H and Baglioni P 2003 J. Phys. Chem. B 107 10057-62

[22] Fratini E, Chen S H, Baglioni P, Cook J C and Copley J R D 2002 Phys. Rev. E 65010201

[23] Damasceni A, Dei L, Fratini E, Ridi F, Chen S H and Baglioni P 2002 J. Phys. Chem. B $10611572-8$

[24] Ridi F, Fratini E, Milani S and Baglioni P 2006 J. Phys. Chem. B at press

[25] Ridi F, Dei L, Fratini E, Chen S H and Baglioni P 2003 J. Phys. Chem. B 107 1056-61

[26] Callaghan P T 1991 Principles of Nuclear Magnetic Resonance Microscopy (Oxford: Clarendon)

[27] Drews A R, Barker J G, Glinka C J and Agamalian M 1998 Physica A 241-243 189-91

[28] Schwahn D, Miksovsky A, Rauch H, Seidl E and Zugarek G 1985 Nucl. Instrum. Methods Phys. Res. A 239 229-34

[29] Singh M A, Ghosh S S and Shannon R F 1993 J. Appl. Crystallogr. 26 787-94

[30] Faraone A, Chen S H, Fratini E, Baglioni P, Liu L and Brown C 2002 Phys. Rev. E 65040501

[31] Faraone A, Fratini E, Baglioni P and Chen S H 2004 J. Chem. Phys. 121 3212-20

[32] Fratini E, Chen S H, Baglioni P and Bellissent-Funel M C 2001 Phys. Rev. E 64 1-4

[33] Fratini E, Faraone A, Baglioni P, Bellissent-Funel M C and Chen S H 2002 Physica A 304 1-10

[34] Ridi F, Fratini E, Mannelli F and Baglioni P 2005 J. Phys. Chem. B 109 14727-34

[35] Alesiani M, Capuani S, Giorgi R, Maraviglia B, Pirazzoli I, Ridi F and Baglioni P 2004 J. Phys. Chem. B 108 4869-74

[36] Ridi F, Fratini E, Giorgi R and Baglioni P 2006 J. Phys. Chem. B to be submitted

[37] Chen S H, Liao C, Sciortino F, Gallo P and Tartaglia P 1999 Phys. Rev. E 59 6708-14

[38] Zanotti J-M, Bellissent-Funel M C and Chen S H 1999 Phys. Rev. E 593084

[39] Gotze W and Sjogren L 1992 Rep. Prog. Phys. 55241

[40] Bengtzelius U, Gotze W and Sjolander A 1984 J. Phys. Chem. 175915

[41] Baglioni P, Fratini E and Chen S H 2002 Appl. Phys. A 74 S1178-81

[42] Zanotti J-M, Bellissent-Funel M C and Chen S H 1999 Phys. Rev. E 59 3084-93

[43] Fujii K and Kondo W 1974 J. Am. Ceram. Soc. 57 492-7

[44] Berliner R, Popovici M, Herwig K W, Berliner M, Jennings H M and Thomas J J 1998 Cem. Concr. Res. $28231-43$

[45] Brown M E, Dollimore D and Galwey A K 1980 Comprehensive Chemical Kinetics vol 22, ed C H Bamford and C F H Tipper (Amsterdam: Elsevier)

[46] Brown M E (ed) 1998 Handbook of Thermal Analysis and Calorimetry. Principles and Practice vol 1 (Amsterdam: Elsevier)

[47] Garrault S, Behr T and Nonat A 2006 J. Phys. Chem. B $110270-5$

[48] Avrami M 1939 J. Chem. Phys. 7 1103-12

[49] Avrami M 1940 J. Chem. Phys. $8212-24$

[50] Avrami M 1941 J. Chem. Phys. 9 177-84

[51] FitzGerald S A, Neumann D A, Rush J J, Bentz D P and Livingston R A 1998 Chem. Mater. 10 $397-402$

[52] Yu P, Kirkpatrick R J, Poe B, McMillan P F and Cong X 1999 J. Am. Ceram. Soc. $82742-8$

[53] Cupane A, Levantino M and Santangelo M G 2002 J. Phys. Chem. B 106 11323-8

[54] Angell C A and Rodgers V 1984 J. Chem. Phys. $806245-52$

[55] Dickens B and Dickens S H 1999 J. Res. Natl Inst. Stand. Technol. 104 173-83

[56] Fateley W G and Chaffin N 1999 Development of a Field-Portable Near-Infrared Water-Cement Ratio Meter. Phase I: Investigation of Spectral Feasibility Kansas Department of Transportation Materials Research Center

[57] Thomas J J and Jennings H M 1999 Chem. Mater. 11 1907-14

[58] Brown P W, Pommersheim J and Frohnsdorff G 1985 Cem. Concr. Res. 15 35-41

[59] Tenoutasse N and Donder A 1970 Silicates Industriels 35301

[60] Escalante-Garcìa J I and Sharp J H 1998 Cem. Concr. Res. 28 1245-57

[61] Massazza F and Daimon M 1992 9th Int. Congress on the Chemistry of Cement (New Delhi, India)

[62] Guinier A and Fournet G 1955 Small Angle Scattering of X-rays (New York: Wiley)

[63] Sabine T M et al 1995 Mater. Res. Soc. Symp. Proc. 376499

[64] Phair J W, Schulz J C, Bertram W K and Aldridge L P 2003 Cem. Concr. Res. 33 1811-24 